\title{
Use of Host-Plant Trait Space by Phytophagous Insects during Host-Associated Differentiation: The Gape-and-Pinch Model
}

\author{
Stephen B. Heard \\ Department of Biology, University of New Brunswick, P.O. Box 4400, Fredericton, NB, Canada E3B 5A3 \\ Correspondence should be addressed to Stephen B. Heard, sheard@unb.ca
}

Received 22 July 2011; Accepted 6 November 2011

Academic Editor: Andrew Hendry

Copyright () 2012 Stephen B. Heard. This is an open access article distributed under the Creative Commons Attribution License, which permits unrestricted use, distribution, and reproduction in any medium, provided the original work is properly cited.

Ecological speciation via host shifting has contributed to the astonishing diversity of phytophagous insects. The importance for host shifting of trait differences between alternative host plants is well established, but much less is known about trait variation within hosts. I outline a conceptual model, the "gape-and-pinch" (GAP) model, of insect response to host-plant trait variation during host shifting and host-associated differentiation. I offer four hypotheses about insect use of plant trait variation on two alternative hosts, for insects at different stages of host-associated differentiation. Collectively, these hypotheses suggest that insect responses to plant trait variation can favour or oppose critical steps in herbivore diversification. I provide statistical tools for analysing herbivore trait-space use, demonstrate their application for four herbivores of the goldenrods Solidago altissima and S. gigantea, and discuss their broader potential to advance our understanding of diet breadth and ecological speciation in phytophagous insects.

\section{Introduction}

The insects have long been held up as providing spectacular examples of rapid diversification and high standing diversity (e.g., [1-3]). Among insects, phytophagous clades often undergo dramatic radiations [4], and phytophagous lineages tend to be more diverse than their nonphytophagous sisters $[5,6]$. One likely driver of diversification among phytophagous insects is their tendency to specialize on hostplant species or organs [7-10] and to diversify via host or organ shifts followed by host-associated differentiation (HAD), the evolution of new specialist races or species [9, 11-14]. Because many cases of HAD appear to have proceeded in sympatry [15], a great deal of theoretical and empirical work has focused on understanding ways in which adaptation to different host plants can impose disruptive selection on nascent specialist forms and also reduce gene flow (or permit differentiation in the face of gene flow) between those forms [14-16]. Phytophagous insects, along with parasitoids [17], freshwater fishes [18], seed-eating birds [19], and habitat-specialist plants [20] and lizards [21] have therefore been central to the development of ideas about ecological speciation [22].
A common theme among case studies of ecological speciation is the existence of two alternative niches-microhabitats, resources, reproductive strategies, and so forththat can be exploited by individuals of a single species, with the potential for disruptive selection to operate between the alternative niches. For phytophagous insects, the alternative niches are a pair of host plant species (or organs). One commonly imagines an evolutionary sequence beginning with an insect exploiting only one of the two alternative hosts. Perhaps via host-choice errors, some individuals occasionally attack individuals of the second host, and if fitness penalties for doing so are not too severe, a host shift occurs and the insect begins to exploit both alternative hosts. (Description of these events as "errors" is standard in the plant-insect literature, but of course this usage is teleological shorthand and can conceal interesting biology. For instance, it might be that genotypes with strong enough host preferences to avoid "errors" would also show costly rejection of some suitable hosts; in this case, the occurrence of host-choice "errors" is simply an adaptive compromise. Nonetheless, for simplicity I retain the standard usage here). Disruptive selection can now begin to favour genotypes better adapted to each alternative host. If reproductive isolation arises between nascent forms, 
then ecological speciation can proceed, and a single (perhaps polymorphic) generalist is replaced with a pair of hostspecialist races or species. Because reproductive isolation is expected to take some time to evolve, if it can evolve at all, different insects exploiting a pair of alternative host plants are expected to fall on a continuum from generalists to nascent, poorly differentiated host forms to distinct host-specialist sister species $[13,23]$. There will be analogous continua for ecological speciation across other kinds of alternative niches, for instance, in parasitoids speciating across hosts or fish across depth niches (e.g., [17, 24]).

The process of HAD in phytophagous insects has been widely discussed, both in general [14] and in the context of a few well-studied model systems (e.g., apple maggot fly [25, 26], goldenrod ball-gall fly $[27,28]$ ). Perhaps unsurprisingly, nearly all studies of HAD have emphasized insect responses to differences in plant traits between the alternative hosts, while downplaying variation in plant traits among individuals within each host. Such an interspecific perspective is obviously appropriate for studies using population-genetic tools to detect host-associated forms and reconstruct their history (e.g., [13, 29-31]), but it is also near universal in studies discussing ecological mechanisms by which host shifts and HAD proceed (e.g., [25, 26, 28, 32-38]). An alternative approach would explicitly recognize within-species variation in host-plant traits and consider possible roles for such variation in favouring or impeding host shifting and HAD. This approach has yet to be applied in earnest to any system, but intriguing hints at its usefulness appear in the literature for the goldenrod ball-gall fly, Eurosta solidaginis, and its races on the goldenrods Solidago altissima and S. gigantea. For example, Eurosta of the S. altissima race prefer the largest ramets of their host [39], and since S. gigantea plants tend to be shorter when Eurosta oviposits [40], this preference might discourage host-choice errors by altissima flies. In contrast, if gigantea flies similarly prefer taller ramets, they could be susceptible to host-choice errors (although gigantea flies' preferences have not been assessed, and neither hypothesis raised here appears to have been tested). Work on the phenology of insect emergence and host-plant growth has similar implications. Eurosta adults emerge from $S$. gigantea earlier than from S. altissima [41], and this pattern is correlated with availability of rapidly growing ramets of each host to be attacked [40]. Thus, individual S. altissima ramets with earlier phenology, or S. gigantea ramets with later phenology, might be more likely to be attacked by the "wrong" host race. There is geographic variation in the abundance of such intermediate-phenology ramets, and How et al. [40] suggested that host shifts might be more easily initiated where host phenology overlaps more extensively.

Even for Eurosta, however, there are few plant traits for which insect responses have been studied on both alternative hosts, and so we know little about how insect responses to plant trait variation might relate to the ecology of host shifting and HAD. Furthermore, there is no system for which we can compare insect responses to plant trait variation for a set of insects attacking the same plants but differing in stage of host shifting and HAD. I outline here a conceptual model of host trait-space use during host shifting and HAD, along with a statistical approach for investigating trait-space use in phytophagous insects. I suggest hypotheses for temporal changes in host trait-space use over evolutionary time, from initial host-choice errors through to the independent evolution of a pair of well-isolated host-specialist sibling species. I call the overall model the "gape-and-pinch," or "GAP," model of trait-space use (the reason for this name will be apparent after the model is described). While I outline the model for plants and phytophagous insects, it will apply to many other systems with some straightforward vocabulary substitutions.

\section{Conceptual "GAP" Model of Host Trait-Space Use}

All plant species vary intraspecifically for numerous morphological, phenological, and chemical traits, with variation having genetic, epigenetic, and/or environmental causes (e.g., [42-45]). This variation defines a set of phenotypes that are available for attack by a phytophagous insect searching its environment for suitable hosts. This set of phenotypes can be depicted as a cloud of points in a multidimensional trait space, with each point representing an individual plant (or a ramet, for clonal plants; or even a module, when important variation occurs within individuals [46]). It is convenient to consider the two-dimensional case (Figure 1), which can represent either a system in which two plant traits show variation relevant to insect attack or a two-dimensional summary of a higher-dimensional trait space (using principal components to extract two dominant axes of trait variation). I use the term "available trait space" to describe this cloud of points, as combinations of plant traits falling inside it are available to attacking herbivores, while combinations outside are not available (i.e., they do not correspond to real plants which might be attacked). This trait space can be characterized by calculating its centroid (the point whose coordinate on each axis is the mean value of that coordinate for all individuals), its size (average distance from individual plants to the centroid), and its shape.

Consider first an insect interacting with a single host species. Some plant individuals will be attacked, but others will likely escape. The attacked individuals define the "attacked trait space" (filled circles in Figure 1), which must be a subset of the available trait space (and might be expected to be a smaller subset for more specialist herbivores $[47,48])$. The relationship between available and attacked trait spaces will depend on active host-selection behavior by insects (insect preference), and also on whether insects can survive on an individual plant after initiating attack (insect performance). Both preference and performance will depend on plant traits-sometimes the same traits, but sometimes not. For simplicity, I use "herbivore attack" to denote the occurrence of feeding herbivores on plants, whether patterns in occurrence arise from preference or performance, and terms like "selective" attack should similarly be taken to include both preference and performance effects. The attacked trait space may represent a common preference by all herbivore individuals, or the sum of herbivore individuals' distinct preferences in species with strong individual specialization $[49,50]$. 


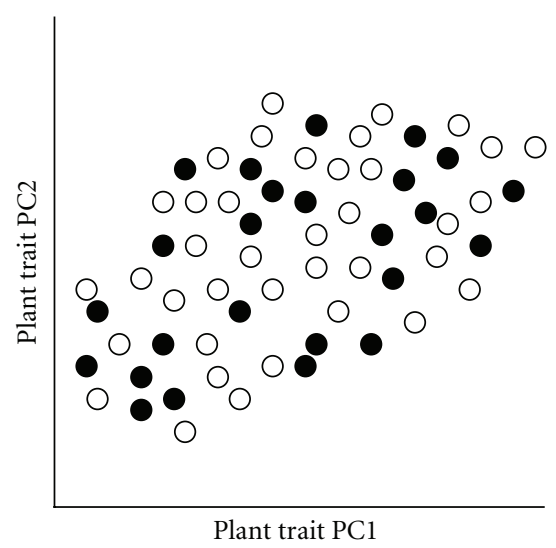

(a)

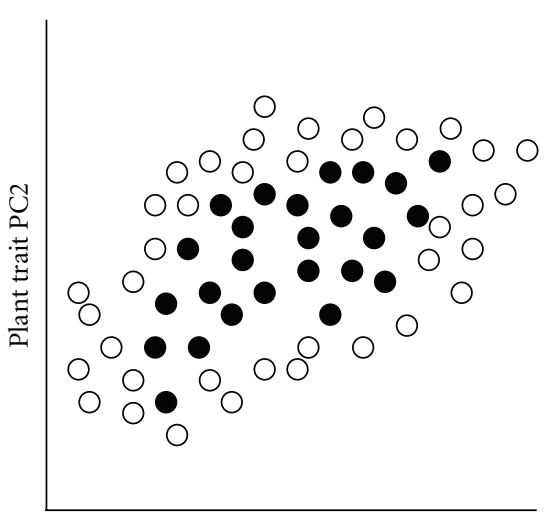

Plant trait PC1

(b)

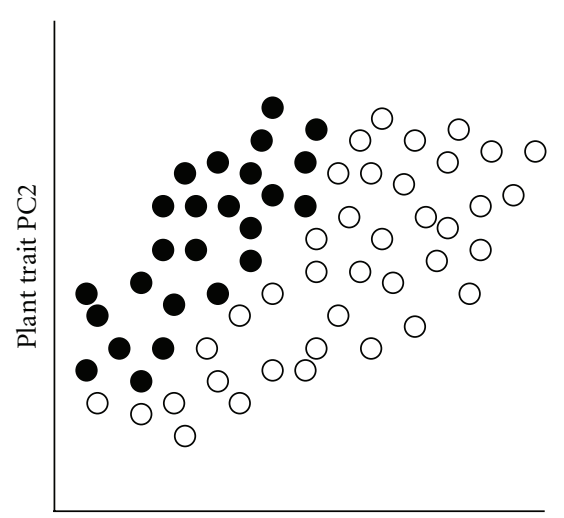

Plant trait PC1

(c)

Figure 1: Possible patterns of host trait-space use by herbivorous insects. Available host-plant individuals form a cloud in trait space (which is likely multidimensional, but summarized here by the first two principal component axes). Open circles denote unattacked plants, and filled circles attacked ones.

When herbivore attack is random with respect to plant traits (Figure 1(a)), the attacked trait space will resemble the available trait space in centroid location, shape, and (once corrected for the smaller number of attacked plants) size. For a selective herbivore (one that rejects some available plants), in contrast, the attacked and available trait spaces will differ. Many patterns are possible, but two are particularly likely. First, the herbivore might attack typical plants (those with trait values near the population means) and reject extreme ones, leading to an attacked trait space that is central with respect to the available trait space: the attacked space is smaller than the available space, but the two spaces have similar centroids (Figure 1(b)). Such a pattern might be favoured by selection because (for example) typical plants are most common, and insects preferring them pay lower search costs and experience greater resource availability. Alternatively, herbivore attack might be associated with extreme trait values (e.g., herbivores might perform best on the largest or least-defended individuals), leading to an attacked trait space that is marginal with respect to the available trait space: the attacked trait space is again restricted in size, but in this case the two spaces have different centroids (Figure 1(c)).

Now consider a pair of plant species available for attack (Extension to larger numbers of hosts is possibly but considerably complicating.) Given a common set of measured traits, we should see two clouds of points in trait space (Figure 2) defining a pair of available trait spaces. The distance between available trait spaces defined by different plant species might be large compared to the size of each available trait space [38], but, for closely related pairs of phenotypically variable plants, this need not be so (e.g., for Solidago altissima and S. gigantea, see Figure 3). Two available trait spaces could even be touching or interdigitated, especially for hybrid swarms [51]. One can again consider attacked trait spaces in comparison to available trait spaces on each host, but now there are many more possibilities, as each attacked trait space could be nonselective, central, or marginal (and if marginal, toward or away from the other host). Among possible patterns, I emphasize here a set of trait-space relationships predicted for an insect herbivore moving through a four-step evolutionary sequence: from original specialization on one of the two hosts, through a host shift, to early and late stages of HAD.

\subsection{Stage 1: Single-Host Specialists and the Importance of} Host-Choice Errors. An insect attacking a single host could show virtually any pattern in the relationship between attacked and available trait spaces, but some patterns are of special interest in the context of possible host-shifting to an evolutionarily novel host. (By a "host shift" I mean the addition of a novel plant to the herbivore species' diet, which will normally occur without immediate abandonment of the old). Such host shifts are likely to begin when a few individuals attack the "wrong" (novel) host, making it possible for selection to favour the incorporation of the novel host into the insect's host range. Importantly, the likelihood of host-choice errors is likely to depend on the insect's use of plant trait space. In particular, imagine an insect showing a marginal attacked trait space on the ancestral host. That marginal attacked trait space could be adjacent to the available trait space defined by the novel host (Figure 2(a)), or could be distant from it. When it is adjacent, host-choice errors are more likely and insects making those errors are more likely to survive on the novel host [52]. In contrast, when the ancestrally attacked trait space is distant from the novel host, host-choice errors (and thus host shifting) should be less likely. I call this the "adjacent errors hypothesis." The logic mirrors the widespread expectation that hostchoice errors and host shifts are more likely between species that resemble each other morphologically, chemically, or phylogenetically [38] but stresses that the distance in trait space that needs to be crossed for a host-choice error depends not only on the distance between available trait spaces but also on how insect preference and performance define the attacked trait space.

2.2. Stage 2: Oligophagous Feeding Following Diet Expansion. Following a host shift that expands diet, our focal insect 


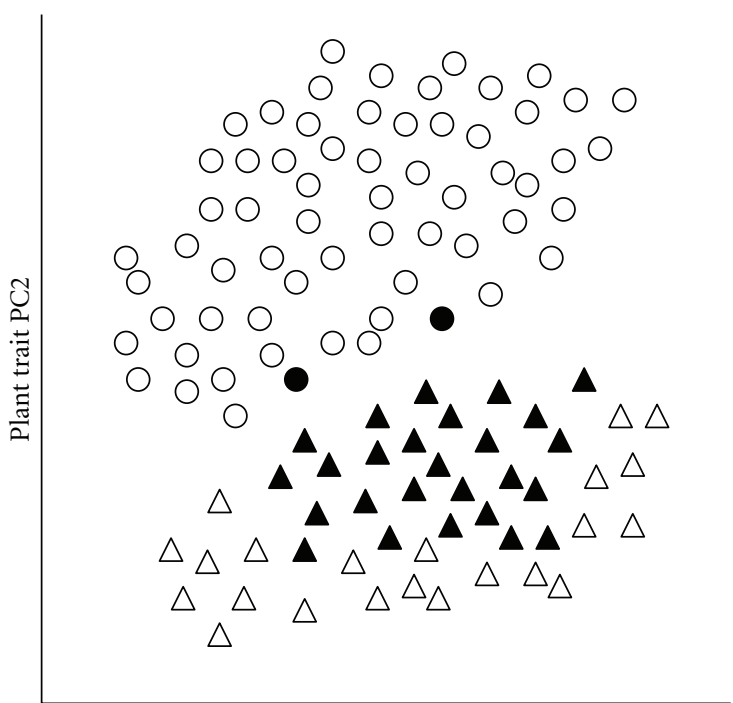

Plant trait PC1

(a)

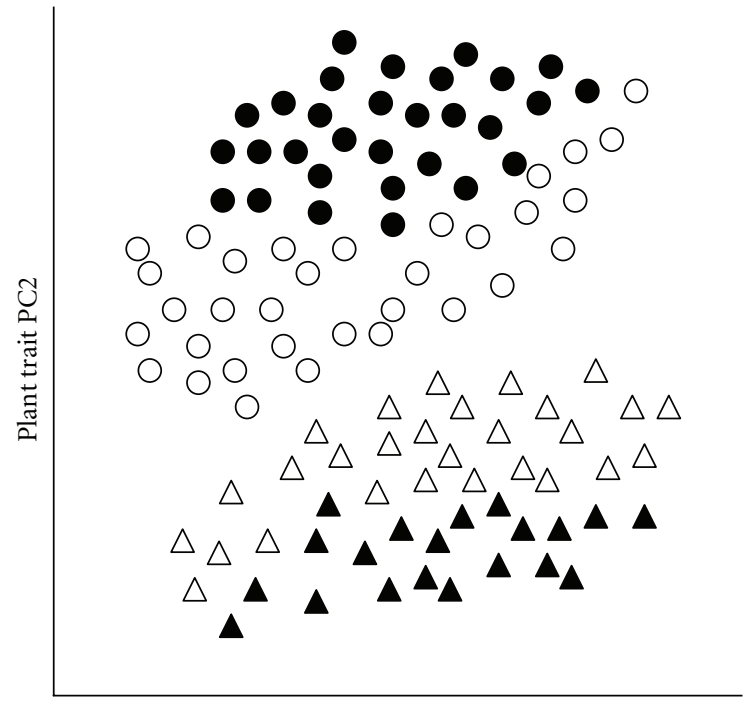

Plant trait PC1

(c)

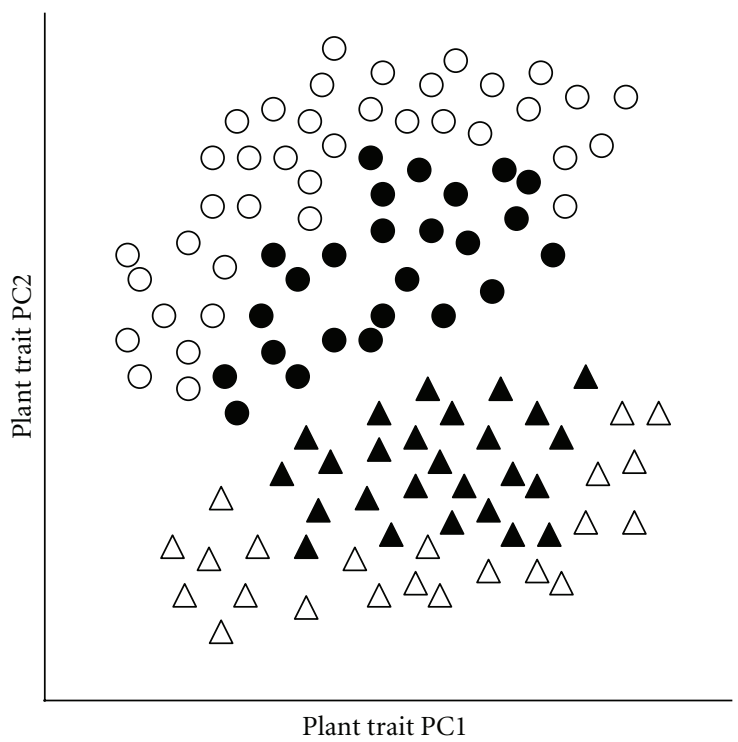

(b)

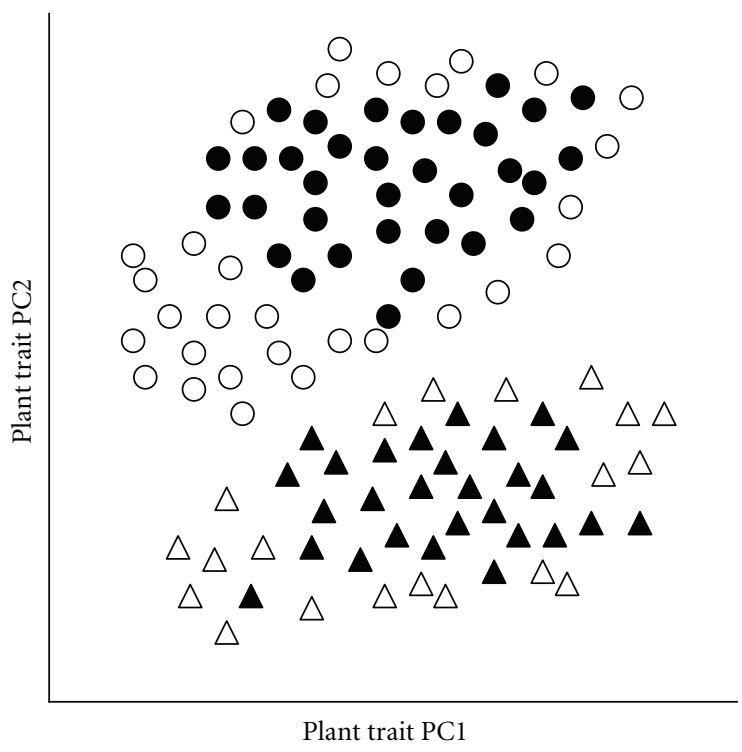

(d)

FIGURE 2: Some possible relationships between attacked trait spaces on two alternative host plants. Illustrated are hypothetical relationships for four stages during a host shift and subsequent host-associated differentiation. (a) Specialist on host 1, predisposed to host-choice errors due to marginal attack on trait space adjacent to the alternative host. (b) Following diet expansion, herbivore is oligophagous accepting both hosts; selection favours central attack on the combined trait space. (c) Early evolution of host-associated differentiation: use of marginal and distant trait spaces on the two hosts reduces host-choice errors and hence gene flow. (d) Reproductively isolated monophagous specialists on each host: selection favours central attack by each specialist on the trait space of its host. See text for further discussion of these scenarios.

species will be oligophagous, feeding on two hosts (ancestral plus novel) rather than one. Because this stage should follow from patterns in attack allowing host-choice errors (adjacent errors hypothesis), attacked trait space is likely to remain marginal on the ancestral host (Figure 2(a)). As host preference and performance evolve to include attack on the novel host, the attacked trait space on that host is likely to be marginal as well, but with the two attacked trait spaces adjacent (Figure 2(b)) because novel plants closer to the ancestrally attacked trait space are more easily colonized. I call this the "adjacent oligophagy hypothesis."

Note that the adjacency pattern is equivalent to restricted but central use of an available trait space defined by the two hosts in combination (compare Figures 1(b) and 2(b)). If disruptive selection between alternative hosts does not act or is not powerful, oligophagy and the adjacency pattern could be evolutionarily persistent. Alternatively, this stage might be transient, persisting only until disruptive selection has 
time to drive HAD of insect subpopulations exploiting the two hosts. The contrast between these possibilities highlights an important fork in the evolutionary road [53], in which disruptive selection favouring HAD is or is not sufficient to overcome gene flow working to homogenize the herbivore population and to maintain an oligophagous diet.

\subsection{Stage 3: Nascent Host-Specialist Forms and the Selection-} Gene Flow Tension. How might insect trait-space use favour or oppose the ability of disruptive selection to achieve HAD? Craig et al. [52] argued that persistent oligophagy is likely when the two available trait-spaces are very close, with HAD likely when they are more distant. However, their conceptual model assumes that attacked trait spaces on the two hosts remain indefinitely adjacent (their Figure 1). I suggest that there is another important possibility; a critical step in HAD may be the separation of the attacked trait spaces (Figure 2(c)) such that insect subpopulations on the two hosts (now appropriately thought of as nascent host forms) come to attack dissimilar individuals rather than similar ones. I call this the "trait distance-divergence hypothesis". Separation of the two attacked trait spaces could arise in two different but complementary ways.

First, distance between attacked trait spaces could arise simply because disruptive selection for adaptation to the alternative hosts overpowers the homogenizing effect of gene flow between nascent host forms. Under this scenario, the attacked trait spaces could move to opposite ends of the available trait spaces, as in Figure 1(c), or merely further apart than adjacency, depending on the shape of the fitness landscape-that is, fitness optima on the alternative hosts might favour central or marginal trait spaces. Under this scenario, distance between attacked trait spaces is just a symptom by which the progress of HAD can be recognized.

Second, distance could be a product of selection to minimize host-choice errors by each nascent host form or hybridization between them [22]. Host-choice errors could be opposed by selection because they lead to preferenceperformance mismatches, or because they put larvae in competition with members of the other host form (encouraging divergence by character displacement). Alternatively, hostchoice errors coupled with the tendency for phytophagous insects to mate on their host plants could lead to hybrid matings. Hybrid disadvantage is possible given tradeoffs in ability to exploit the alternative hosts, or if hybrids prefer or are best suited for trait-value combinations falling in the gap between the two available trait spaces (this gap is shown narrow in Figure 2 but will often be wider [38]). Selection to reduce hybridization by widening the distance between attacked trait spaces (Figure 1(c)) would be a form of reinforcement [54]. Under the reinforcement scenario, distance between attacked trait spaces is more than a symptom of HAD; once achieved, it serves to reduce gene flow between nascent host forms and permit HAD to progress. (In passing, I note that if selection simply overpowers gene flow, we would expect HAD to involve genetic divergence in genomic islands, whereas if selection opposes hybridization, genome-wide genetic divergence should result via "isolation by adaptation") [55-57].
In summary, the trait distance-divergence hypothesis holds that attainment of distance between attacked trait spaces (Figure $1(\mathrm{c})$ ) can be both a symptom of HAD and also a factor permitting HAD. The larger the distance between attacked trait spaces, the more likely is the evolution of genetic differentiation between insects on the two hosts. Since genetic differentiation can ease the evolution of distance between attacked trait spaces, this stage of evolution can involve positive feedback [58-60]. In contrast, an insect for which attacked trait spaces remain adjacent (Figure 1(b)) is likely to remain an oligophagous insect with no hostassociated structure to its gene pool.

\subsection{Stage 4: Pair of Established Host Specialists. As HAD pro-} ceeds and gene flow between nascent host forms declines, we would expect the gradual accumulation of more, and more effective, reproductive isolating mechanisms [24, 61, 62]. This should continue until ecological speciation is complete, and the two host-specialist forms attain the status of full biological species. As reproductive isolation becomes enforced by multiple, redundant mechanisms, the importance of separation between attacked trait spaces should decline. Selection will then be free to mould trait-space use independently for each species, and if reinforcement earlier in HAD pushed the attacked trait spaces apart (trait distancedivergence hypothesis), this force can now relax. If selection favours use of central trait space on each host, for example (Figure 2(d); or if it favours nonselective use of trait space on each host), the distance between the attacked trait spaces should decrease. I call this the "distance relaxation hypothesis."

Note that through the temporal sequence (Figures 2(a)2(d)), the overall conceptual model suggests a pair of attacked trait spaces that begin close together, move apart, and then move back together like pincers. This movement underlies the terminology "gape-and-pinch" model of traitspace use.

2.5. What about Generalists? The foregoing considered insects that begin as monophagous on one of the two hosts and remain narrowly oligophagous or monophagous at all stages of HAD. However, many herbivores are broader generalists [63] for which we would not expect any of the traitspace patterns shown in Figure 2. In particular, it would be very surprising if a broad generalist showed nonrandom separation between attacked trait spaces (Figures 2(c) and 2(d)). Instead, attacked trait space might be nonselective on both hosts $[47,48]$, or restricted but marginal along a trait axis orthogonal to the difference between the two hosts (e.g., insects might prefer larger individuals of each host and also attack other, larger species). Such broad generalists are much less likely than host specialists to undergo HAD because (being already adapted to multiple hosts) they are less likely to experience strongly disruptive selection for performance on one host versus another [64].

2.6. Testing the Hypotheses. The four hypotheses that make up the GAP model are logically distinct; finding that one 
TABLE 1: Relationships between patterns in trait-space use (Figures 2(a)-2(d)), the GAP model, and statistical tests implemented for analysis of attacked trait spaces.

\begin{tabular}{|c|c|c|c|c|}
\hline Pattern in trait-space use & Hypothesis & $\begin{array}{c}\text { Attacked trait spaces } \\
\text { marginal? }^{1}\end{array}$ & $\begin{array}{l}\text { Attacked trait spaces } \\
\text { restricted? }^{1}\end{array}$ & $\begin{array}{c}\text { Attacked trait spaces } \\
\text { distant? }\end{array}$ \\
\hline $\begin{array}{l}\text { Monophagous, attacked } \\
\text { trait space marginal and } \\
\text { adjacent to alternative } \\
\text { host (Figure } 2(\mathrm{a}) \text { ) }\end{array}$ & $\begin{array}{c}\text { Adjacency favours host } \\
\text { shifting (adjacent errors } \\
\text { hypothesis) }\end{array}$ & $\begin{array}{c}\text { Ancestral host: marginal } \\
\text { Novel host: marginal but } \\
\text { rare }^{2}\end{array}$ & - & Attacked spaces close ${ }^{2}$ \\
\hline $\begin{array}{l}\text { Oligophagous, attacked } \\
\text { trait spaces marginal and } \\
\text { adjacent (Figure 2(b)) } \\
\end{array}$ & $\begin{array}{l}\text { Adjacency persists after } \\
\text { host shifting (adjacent } \\
\text { oligophagy hypothesis) }\end{array}$ & $\begin{array}{l}\text { Ancestral host: marginal } \\
\text { Novel host: marginal }\end{array}$ & - & Attacked spaces close \\
\hline $\begin{array}{l}\text { Nascent host races, } \\
\text { attacked trait spaces } \\
\text { marginal and distant } \\
(\text { Figure } 2(\mathrm{c}))\end{array}$ & $\begin{array}{l}\text { Distance permits, and is } \\
\text { also symptomatic of, } \\
\text { genetic isolation (trait } \\
\text { distance-divergence } \\
\text { hypothesis) }\end{array}$ & $\begin{array}{l}\text { Ancestral host: marginal } \\
\text { Novel host: marginal }\end{array}$ & - & Attacked spaces distant \\
\hline $\begin{array}{l}\text { Pair of monophagous } \\
\text { species, attacked trait } \\
\text { spaces central on each } \\
\text { host (Figure } 2(\mathrm{~d}) \text { ) }\end{array}$ & $\begin{array}{c}\text { Other isolating } \\
\text { mechanisms reduce } \\
\text { importance of } \\
\text { trait-space distance } \\
\text { (distance relaxation } \\
\text { hypothesis) } \\
\end{array}$ & $\begin{array}{c}\text { Ancestral host: not } \\
\text { marginal } \\
\text { Novel host: not marginal }\end{array}$ & $\begin{array}{l}\text { Ancestral host: restricted } \\
\text { (central) or nonselective } \\
\text { Novel host: restricted } \\
\text { (central) or nonselective }\end{array}$ & $\begin{array}{l}\text { Attacked spaces neither } \\
\text { close nor distant }\end{array}$ \\
\hline
\end{tabular}

hypothesis holds (or fails) implies nothing about the others. For example, for a given herbivore, the adjacent errors and adjacent oligophagy hypotheses could hold, but the distancedivergence and distance relaxation hypotheses fail, if HAD proceeds to ecological speciation without any movement of attacked trait spaces away from each other following the host shift.

Each of the four hypotheses can also be posed, and tested, at two levels. First, we can test each hypothesis for a single herbivore. For instance, are attacked trait spaces adjacent on Solidago altissima and S. gigantea for the narrowly oligophagous [13] gallmaker Epiblema scudderiana (adjacent oligophagy hypothesis)? Of course, such tests focus on patterns, and confirmation of a pattern need not constitute a strong test of underlying mechanism. Second, and more powerfully, we can test each hypothesis for herbivorous insects as a class. For instance, are attacked trait spaces (statistically) further apart for recently divergent and incompletely isolated pairs of host races than they are for more ancient specialist species pairs (distance relaxation hypothesis)? At this level, the hypotheses can hold strongly or weakly (or not at all); that is, the empirical relationship between trait-space distance and extent of reproductive isolation could be stronger or weaker (or non-significant).

Testing the adjacent errors, adjacent oligophagy, trait distance-divergence, and/or distance relaxation hypotheses for individual herbivores will require trait-space use data for large numbers of individuals on the alternative hosts. Some tests will be difficult at the individual-herbivore level (e.g., testing the distance relaxation hypothesis for an individual herbivore would require historical data on past trait-space use, which will only rarely be available). Ultimately, though, assessment of the GAP model depends more on comparative tests of the hypotheses for herbivores as a class, and this will require data on host trait-space use for multiple insect herbivores differing in host range. A particularly revealing approach will involve sets of herbivores that differ in the extent of their progression through HAD (e.g., [13]), because of the expectation that the trait-space relationships shown in Figures 2(a)-2(d) form a temporal evolutionary sequence. The cleanest comparative tests will involve herbivores sharing a common pair of alternative hosts, so that attacked trait spaces can be contrasted among herbivores (e.g., recent host forms and ancient specialist pairs, for the distance relaxation hypothesis) while seen against the simple backdrop of a common pair of available trait spaces.

Progress towards understanding the influence of traitspace use on the evolutionary trajectory of herbivore specialization, then, can be made by measuring for multiple insect herbivores the relationships between available and attacked trait spaces on the alternative hosts, for comparison with those suggested by the four hypotheses (summarized in Table 1). In particular, we will be interested in whether attacked trait space on each host is marginal (and in what direction), and whether the two attacked trait spaces are adjacent or distant.

Unfortunately, we do not yet have sufficient comparative data to test the GAP model. Members of my laboratory are beginning to gather such data for insect herbivores attacking the goldenrods Solidago altissima and S. gigantea. In following sections, I provide formal statistical tools for analysis of such data and apply them to an illustrative data set demonstrating a path towards the comparative hypothesis tests that are our ultimate goal. 


\section{Statistical Methods}

I developed statistical methods to test for three patterns in host trait-space use by insect herbivores. These patterns are predicted, in different combinations, by the adjacent errors, adjacent oligophagy, distance-divergence, and distance relaxation hypotheses (Table 1) and thus provide windows on the overall GAP model. The tests share a common framework in that they are based on relationships between attacked and available trait spaces for host plants of two species (Figures 1 and 2). Two tests pertain to the pattern of attack on a single host, and the third to the pattern of attack on each host relative to the other.

First, I test for central versus marginal location of the attacked trait space on each host ("Marginal trait-space test"). I calculate the centroid of the available trait space (mean PC1 and PC2 scores for all available plants, attacked and unattacked) and that of the attacked trait space (mean PC scores for attacked plants only). I then calculate the distance between available and attacked centroids and compare this to a null distribution of 10,000 such distances calculated following random shuffling of attack status across all plant individuals. The fraction of randomization distances larger than the actual attacked-available distance is a $P$ value, and when it is small we reject the null hypothesis that attacked and available plants have a common centroid (central or nonselective attack, Figures 1(a) and 1(b)) in favour of the alternative of marginal attack (Figure 1(c)).

When we are unable to detect marginal use of available trait space, we might seek to distinguish between nonselective (Figure 1(a)) and restricted but central (Figure 1(b)) alternatives. To do so, I use the "restricted trait-space test." I calculate the Euclidean distance from each attacked plant to the centroid of attacked trait space. The size of the attacked trait space is given by the sum of these distances. I then compare this trait-space size to a null distribution the sizes of 10,000 attacked trait spaces generated by randomly shuffling attack status across all plant individuals. Note that shuffling attack status maintains the number of attacked plants, which is critical when calculating the size of a trait space. The fraction of randomization attacked trait spaces smaller than the actual one is a $P$-value, and when it is small we reject the null hypothesis that attack is nonselective. Since we are using the restricted trait-space test following a nonsignificant marginal trait-space test, the alternative is that herbivores exploit a restricted but central subset of available trait space.

Finally, I test whether the distance between attacked centroids on the two host plants is smaller or larger than expected at random ("Distant trait-spaces test," Figure 2(b) versus 2(c)). I first calculate the distance between attacked trait-space centroids on the two alternative hosts. This distance is compared, in a two-tailed test, to a null distribution of 10,000 such distances calculated following random shuffling of attack status across individuals of each plant species (separately). When the actual centroids are farther apart than the mean distance from randomizations, then twice the fraction of randomization distances that are larger than the actual distance is a $P$-value, which when small supports rejection of the null hypothesis in favour of the alternative that the two attacked trait spaces are significantly distant. On the other hand, when the actual centroids are closer than the mean distance from randomizations, then twice the fraction of randomization distances that are smaller than the actual distance is a $P$-value, which when small supports rejection of the null hypothesis in favour of the alternative that the two attacked trait spaces are significantly adjacent.

The marginal trait-space, restricted trait-space, and distant trait-space tests are implemented in TraitSpaces 1.20, a program written in Microsoft Visual Basic.NET for Windows. The software takes as input a datafile with a row for each individual host plant, and columns for host species identity, presence/absence of each herbivore, and first and second principal components calculated from the host trait matrix. (Principal components may be output from any standard statistical package.) Extension to trait spaces of higher dimensionality, if desired, is straightforward; one could even use an unreduced trait matrix at the cost of some complexity in displaying results. The analytical framework easily accommodates data for other host/attacker systems and could even be applied to cases where consumers use variable microhabitats or food resources. The current version of the TraitSpaces package is available from the author on request.

\section{Field Methods}

4.1. Study System. The goldenrods Solidago altissima L. and S. gigantea Ait. are clonal perennials codistributed over much of eastern and central North America. Intermixed stands of the two species are common in open habitats such as prairies, old fields, roadsides, and forest edges. Individual ramets grow in spring from underground rhizomes, flower in late summer and fall, and die back to ground level before winter. The two species differ most obviously in pubescence [65]: S. altissima stems are sparsely to densely short-hairy, especially basally, while $S$. gigantea stems are typically glabrous. Both species display extensive intraspecific variation (genetic and plastic) in most traits, including ramet size, pubescence, leaf shape, size, and toothiness, and chemical profiles $([27,66,67]$, S. B. Heard, unpubl. data).

S. altissima and S. gigantea are attacked by a diverse fauna of insect herbivores [68-70], which vary in diet specialization. Some are broad generalists that accept Solidago as part of a taxonomically diverse diet (e.g., the exotic spittlebug Philaenus spumarius [71]), and some are broadly oligophagous, feeding on Solidago among other members of the Asteraceae (e.g., the chrysomelid Exema canadensis [72]). Others are more narrowly oligophagous, attacking only Solidago spp. (e.g., the tortricid stem-galler Epiblema scudderiana $[13,73])$. Finally, at least four herbivores have evolved monophagous host races or cryptic species on S. altissima and S. gigantea $[13,30,74,75]$, with divergence ranging from quite recent for the ball-gall fly Eurosta solidaginis (at most 200,000 years, but likely much less) to $>2 \times 10^{6}$ years old for the bunch-gall flies Rhopalomyia solidaginis/R. capitata.

Especially for the better-studied S. altissima, attack by various herbivores is known to vary among clones $[68,76$, $77]$, and with plant traits including ramet size $[39,78]$, 


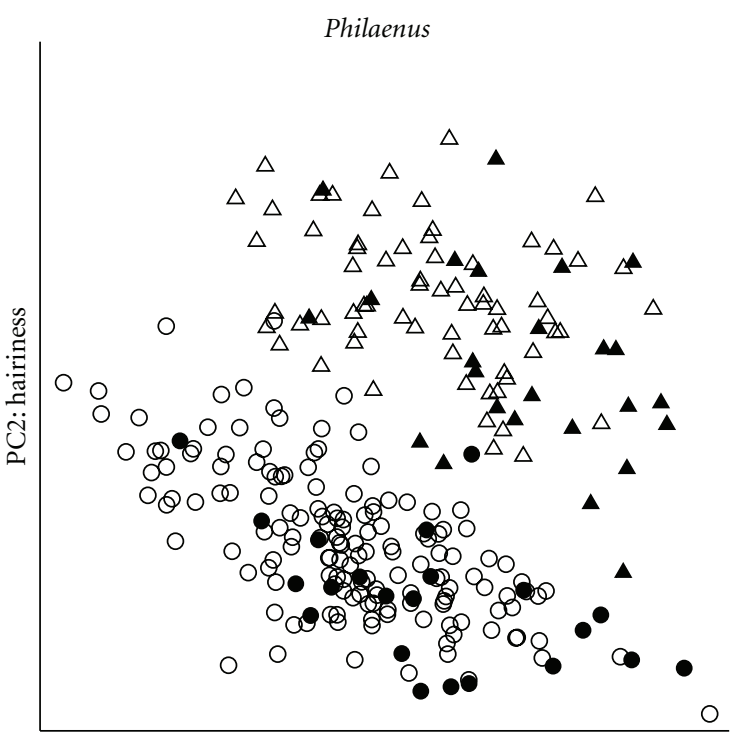

PC2: size

(a)

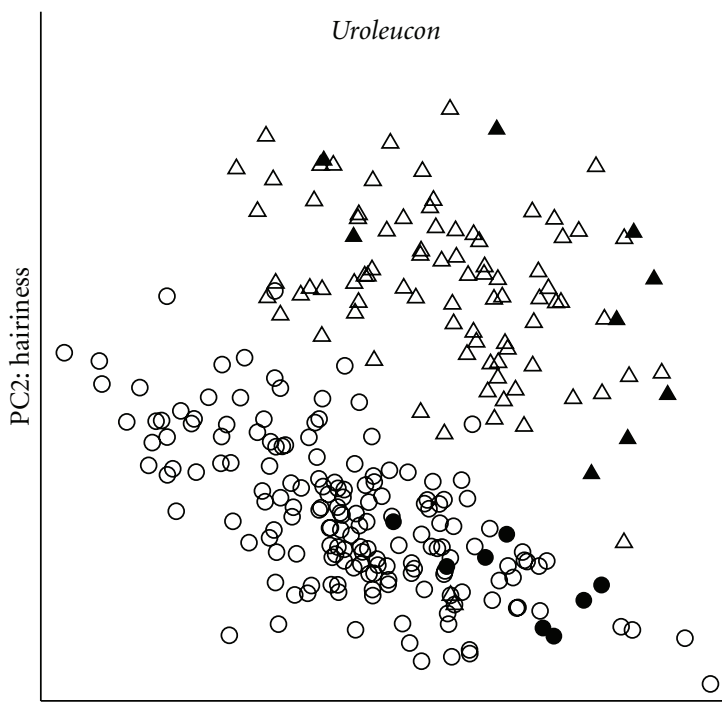

PC2: size

(c)

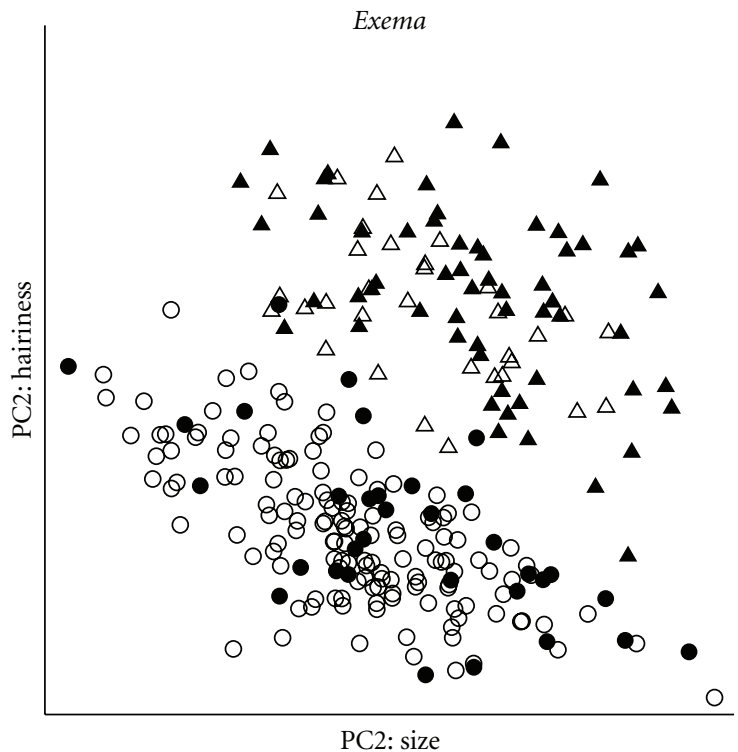

(b)

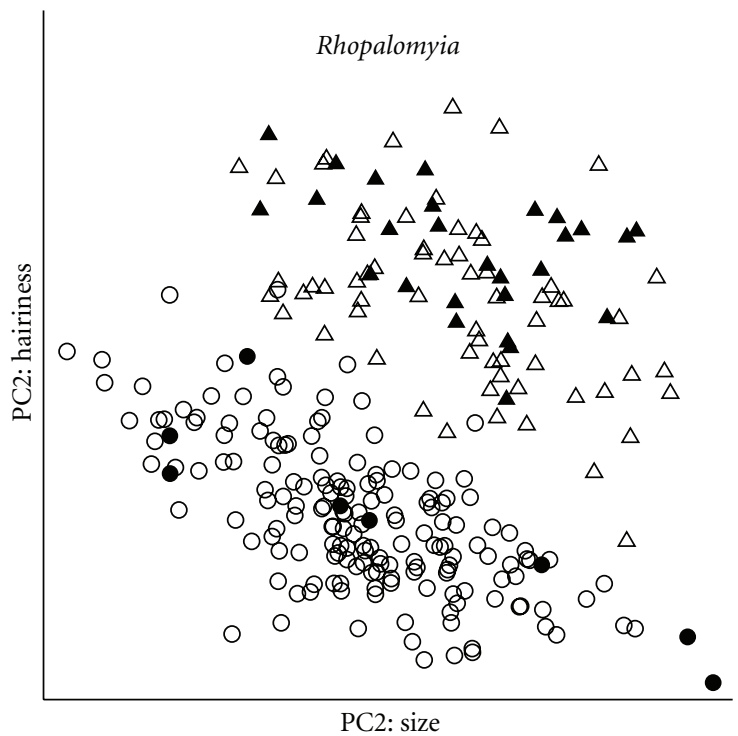

(d)

FIGURE 3: Attacked trait spaces for four goldenrod herbivores on S. altissima (triangles) and S. gigantea (circles). Filled symbols denote attacked plants, and open symbols unattacked ones. Axis labels are shorthand for the first two principal components from a 7-variable morphological dataset; full factor loadings are provided in Table 2.

growth rate [79], nutritional status [80, 81] and ploidy where this varies locally [82]. These trait-attack relationships involve both plant resistance and insect preference [27] and may be concordant or discordant among different herbivore species $[68,82]$.

4.2. Field Data. I and my field team gathered data on plant traits and herbivore attack in old-field and trailside Solidago populations in Fredericton, NB, Canada ( $45^{\circ} 57^{\prime} 30^{\prime \prime} \mathrm{N}, 66^{\circ}$ $\left.37^{\prime} 1-20^{\prime \prime} \mathrm{W}\right)$. Here both $S$. gigantea and S. altissima are abundant along with S. rugosa, S. juncea, S. canadensis, Euthamia graminifolia, Symphyotrichum spp., and other Asteraceae. S. altissima is exclusively hexaploid in the east, and
S. gigantea exclusively diploid, so effects of ploidy on herbivore attack [83] need not be considered here.

It is important to assess the available and attacked trait spaces using traits measured before herbivore attack; otherwise, herbivore responses to plant traits could be confounded with herbivore-driven changes in the same traits. In early June 2004, we marked 104 S. altissima ramets and 186 $S$. gigantea ramets by setting line transects through wellmixed patches of the two species and marking each ramet touched by the line. At the time of marking, a few ramets had already been attacked by the stem-galler Gnorimoschema gallaesolidaginis (Lepidoptera: Gelechiidae; galls on 4 S. altissima and 3 S. gigantea ramets), but other herbivores 
TABLE 2: Correlations among morphological variables measured for S. altissima and S. gigantea.

\begin{tabular}{|c|c|c|c|c|c|c|}
\hline & Ramet height & Leaf length & Leaf width & Teeth & Water content & Trichomes \\
\hline Stem width & 0.88 & 0.72 & 0.18 & 0.40 & -0.42 & 0.36 \\
\hline Ramet height & & 0.75 & 0.17 & 0.43 & -0.44 & 0.36 \\
\hline Leaf length & & & 0.47 & 0.56 & -0.23 & 0.12 \\
\hline Leaf width & & & & 0.32 & 0.24 & -0.57 \\
\hline Teeth & & & & & -0.18 & -0.01 \\
\hline Water content & & & & & & -0.48 \\
\hline
\end{tabular}

had yet to attack. We measured 7 morphological traits of our marked ramets, focusing on easily measured traits that were likely to influence herbivore attack, that help distinguish the two study species, or both. We measured stem trichome density by counting, in the field with a hand lens, all trichomes in silhouette along a $10 \mathrm{~cm}$ length of stem just below the terminal bud. We measured stem width $5-10 \mathrm{~cm}$ above ground using a caliper, and stem height (from ground to the base of the terminal bud) using a measuring tape. For the largest leaf from each ramet, we measured leaf length, leaf width at the widest point, and the number of teeth along one leaf edge. Finally, we weighed each largest leaf before and after drying to constant mass at $45-55^{\circ} \mathrm{C}$ and calculated percent water content.

We surveyed marked ramets twice weekly until the end of August, identifying herbivores present as specifically as possible without disturbing them on the plant (for some groups, like larval Trirhabda beetles, species-level identifications require the removal of the insects to the laboratory, and we wanted to leave plants to experience natural levels of herbivory). When herbivores of the same species were present on consecutive surveys, we were usually unable to determine whether they were the same individuals, so rather than count individuals we classified each ramet as attacked or unattacked by each herbivore over the course of the entire season.

Some marked ramets were lost or damaged during the season, leaving 92 S. altissima ramets and 175 S. gigantea ramets with comprehensive herbivory and plant-trait data. Four herbivores were identifiable to species and abundant enough to give our analyses reasonable power: the xylemsucking spittlebug Philaenus spumarius, which is broadly polyphagous [71]; the folivorous chrysomelid beetle Exema canadensis, which is oligophagous with many hosts in the tribe Astereae [72]; the phloem-sucking aphid Uroleucon nigrotuberculatum, which is narrowly oligophagous on Solidago spp. [84]; and the gall-making cecidomyiid fly Rhopalomyia solidaginis/R. capitata, which is a pair of monophagous specialists ( $R$. solidaginis on S. altissima and $R$. capitata on $S$. gigantea [13]). All further analyses use this reduced set of 267 ramets and 4 herbivores.

\section{Field Results and Discussion}

5.1. Plant Traits. Among the 7 measured traits stem width, ramet height, and leaf length were strongly intercorrelated $(0.72<r<0.88)$, suggesting that all three reflect overall ramet size. The other 18 correlations were weak to moderate
TABLE 3: Factor loadings for the first two principal components from the morphological data matrix for S. altissima and S. gigantea.

\begin{tabular}{lcc}
\hline Trait & Loading on PC1 & Loading on PC2 \\
\hline Stem width & 0.50 & 0.04 \\
Ramet height & 0.51 & 0.04 \\
Leaf length & 0.47 & -0.22 \\
Leaf width & 0.14 & -0.63 \\
Teeth & 0.34 & -0.24 \\
Water content & -0.29 & -0.39 \\
Trichomes & 0.34 & 0.58 \\
\hline
\end{tabular}

(Table 2). The first two principal component axes explained $47 \%$ and $28 \%$ of the morphological variance (75\% total), while no other axis explained more than 9.3\%. PC1 largely reflects ramet size (heavy loadings for stem width, ramet height, and leaf length; Table 3), but also leaf toothiness (positively) and water content (negatively). PC2 contrasts trichome counts (strong positive loading; Table 3) with leaf width (strong negative loading) but also includes leaf water content, leaf length, and toothiness (all negative). These two principal components do a good job of capturing both intraspecific and interspecific variation (Figure 3), with $S$. altissima and S. gigantea separated primarily along PC2 (the pubescent $S$. altissima with high scores, and the glabrous $S$. gigantea with low scores).

5.2. Herbivore Use of Phenotype Space. Attack rates by Solidago herbivores are generally low (often 1-10\% or even less), with the exception of some diet generalists and outbreaking species in high-density years ( $S$. Heard, unpubl. data). In our dataset, even though we worked with some of the most common herbivores, only one herbivore on one host had an incidence above 30\% (Exema canadensis on S. altissima, $64 \%$ of ramets attacked). Other herbivore/host combinations had lower incidences, with several less than 10\% (Uroleucon nigrotuberculatum on both hosts and Rhopalomyia capitata on S. gigantea; Table 4).

The patterns I document in trait-space use could have arisen via herbivore preference, or via performance if poor herbivore growth leads to death or departure of herbivores before surveys can detect them. For most herbivores, repeated surveys allow herbivore detection shortly after attack begins, and so preference is the most likely driver of patterns in attack. However, for gallmakers like Rhopalomyia performance at the stage of gall induction could be important. 
TABle 4: Tests of trait-space use on Solidago altissima and S. gigantea for four Solidago herbivores. $P$-values in bold are significant at $\alpha=0.05$.

\begin{tabular}{|c|c|c|c|c|c|c|c|c|}
\hline \multirow[t]{2}{*}{ Herbivore } & \multirow[t]{2}{*}{ Host } & \multirow[t]{2}{*}{$\begin{array}{l}\text { \# Attacked } \\
\text { plants }^{1}\end{array}$} & \multicolumn{2}{|c|}{ Distance from available centroid ${ }^{2}$} & \multirow[t]{2}{*}{$\begin{array}{l}\text { Marginal } \\
\text { trait-space } \\
\text { test } P\end{array}$} & \multirow[t]{2}{*}{$\begin{array}{l}\text { Restricted } \\
\text { trait-space } \\
\text { test } P\end{array}$} & \multirow[t]{2}{*}{$\begin{array}{c}\text { Distance between } \\
\text { attacked } \\
\text { trait-spaces }^{3}\end{array}$} & \multirow[t]{2}{*}{$\begin{array}{l}\text { Distant } \\
\text { trait- } \\
\text { spaces } \\
\text { test } P\end{array}$} \\
\hline & & & PC1 & PC2 & & & & \\
\hline \multirow{2}{*}{ Philaenus } & S. altissima & 25 & 1.00 & -0.50 & $<0.001$ & $-^{4}$ & \multirow{2}{*}{ Small } & \multirow{2}{*}{0.71} \\
\hline & S. gigantea & 22 & 1.11 & -0.52 & 0.001 & - & & \\
\hline \multirow{2}{*}{ Exema } & S. altissima & 59 & 0.30 & 0.05 & 0.023 & - & \multirow{2}{*}{ Small } & \multirow{2}{*}{0.14} \\
\hline & S. gigantea & 33 & 0.65 & 0.04 & 0.023 & - & & \\
\hline \multirow{2}{*}{ Uroleucon } & S. altissima & 9 & 1.39 & -0.10 & 0.007 & - & \multirow{2}{*}{ Large } & \multirow{2}{*}{0.86} \\
\hline & S. gigantea & 8 & 2.32 & -0.62 & $<0.001$ & - & & \\
\hline \multirow{2}{*}{ Rhopalomyia } & S. altissima & 27 & 0.09 & 0.35 & 0.21 & 0.18 & \multirow{2}{*}{ Large } & \multirow{2}{*}{0.80} \\
\hline & S. gigantea & 8 & 0.66 & -0.05 & 0.31 & 1.0 & & \\
\hline
\end{tabular}

${ }^{1}$ Of 92 available S. altissima and 175 available S. gigantea ramets.

${ }^{2}$ Attacked centroid minus available centroid (PC1 and PC2 components). A positive entry means that ramets with a large PC score are more likely to be attacked.

3 "Small" if the two attacked trait spaces are adjacent (Figure 2(b)), and "large" if the two attacked trait spaces are distant (Figure 2(c)).

${ }^{4}$ This test is informative only when the marginal trait-space test is not significant.

Plant genotype effects on gall induction, mismatched with herbivore preference, are known (for example) for Eurosta solidaginis on S. altissima [85].

The two most generalist herbivores (Philaenus and Exema) showed similar patterns in trait-space use (Figures 3(a) and 3(b); Table 4). Both showed significant evidence for nonrandom use of available hosts (marginal trait-space test). For Philaenus on both hosts, attack was concentrated on larger but less pubescent ramets (higher PC1 and lower PC2), while for Exema on both hosts attack was concentrated on larger ramets but did not depend on pubescence (higher PC1). For both species, the distance between attacked traitspaces on S. altissima and S. gigantea was slightly but not significantly smaller than expected under the null (distant trait-spaces test).

For the oligophagous Uroleucon (Figure 3(c)), attack on both hosts was significantly marginal, being concentrated on larger and less pubescent ramets. The distance between the two attacked trait spaces was slightly, but not significantly, larger than expected under the null. Because this herbivore had the smallest sample size (just 17 attacked ramets total), these tests have much less power than for the more common generalists.

For the monophagous Rhopalomyia species pair (Figure 3(d)), there was no evidence on either host for marginal use of trait space, and the restricted trait space test suggests nonselective rather than central use of available trait space (Table 4). The distance between the two attacked traitspaces was slightly, but not significantly, larger than expected under the null. Sample size, however, was very small for $R$. capitata on S. gigantea (8 attacked ramets), so the tests for that species and for the distance between attacked centroids are likely not very powerful.

5.3. Interpretation and Prospects. The clearest pattern in the illustrative dataset is that for three of four herbivores, attack is significantly concentrated on larger ramets (large PC1). The stem gallers Eurosta [39] and Gnorimoschema
[78] also have well-documented associations with larger ramets, something that is common but not universal among phytophagous insects [86, 87]. Such concordance across herbivore species in the use of trait space increases the likelihood of multiple herbivores cooccuring on a single ramet-something very unlikely under the null hypothesis of independent occurrence, since most attack rates are low. Herbivores cooccurring on a plant may compete directly (via resource consumption) or indirectly (via induced resistance) or may even show facilitation [88] although we know little about potential interactions among goldenrod herbivores [89-91]. However, concordance among goldenrod herbivores in use of plant trait space is far from universal $[68,82]$.

How do the illustrative data fit with the GAP model of trait space use during host shifting and HAD laid out above? The tendency for most herbivores to attack larger ramets (larger PC1) generates pattern in trait-space use. However, this shared tendency means that both attacked trait spaces are offset from the available spaces, in parallel and orthogonally to the contrast between alternative host plants (PC2). The distance between attacked trait spaces is unaffected, and so this ramet-size pattern is not directly relevant to the GAP model. Three of the four herbivores analyzed (Philaenus, Exema, and Uroleucon) have host ranges broader than just the S. altissima-S. gigantea pair and might therefore be expected to be rather unselective about traits distinguishing the two hosts. Indeed, Exema showed no offsets between attacked and available trait spaces along the principal components axis contrasting S. altissima and S. gigantea (PC2; Table 4). Philaenus and Uroleucon did show offsets along this axis, but because they were in the same direction and roughly equal on the two hosts, separation of attacked trait-spaces was not significantly large for either herbivore (Table 4 , distant trait spaces test). The fourth herbivore, Rhopalomyia, is a pair of relatively old monophagous species [13]. For such a species pair, the distance relaxation hypothesis suggests that the use of distant trait spaces may no longer be an important barrier to gene flow (Figure 2(d)). Rhopalomyia's use of trait space 
(Table 4: no evidence for marginal attack, and separation between the two attacked trait spaces no larger than expected at random) is consistent with this (Table 1).

Overall, none of the illustrative data are inconsistent with the GAP model, but none of the four herbivores analyzed provides a strong test of its hypotheses. I did not find any examples of the patterns hypothesized for a singlehost specialist making host-choice errors, for a narrowly oligophagous species immediately following a host shift, or for a pair of nascent forms early in HAD (Table 1, Figures $2(\mathrm{a})-2(\mathrm{c}))$. This is not surprising, though, because species known to be in early stages of HAD on S. altissima/S. gigantea, such as the ball-gall fly Eurosta solidaginis and the spindle-gall moth Gnorimoschema gallaesolidaginis, were insufficiently abundant for analysis. At the broader level of hypothesis testing, four herbivores constitute just a small step towards assessing general patterns in trait-space use through HAD and ecological speciation. It will take many studies like mine, with herbivores on Solidago and other plants, before we can assess the generality of patterns in trait-space use.

Because attack rates for most Solidago herbivores are low, achieving powerful hypothesis tests for any herbivore will entail marking very large numbers of ramets - especially since ramet selection must be done before attack begins to avoid distortions of attack-space measurements if trait values change under herbivore attack. In Solidago, for instance, ramet biomass and height are often reduced by herbivory [91-93]. I am currently expanding on the illustrative study with the goal of securing larger sample sizes for the herbivores studied here and acceptable sample sizes for many more herbivores.

Another obvious limitation of the illustrative dataset is that it includes measurements of only seven plant traits, and conspicuously omits leaf-chemistry traits (and ploidy [83], which varies elsewhere but not in New Brunswick). S. altissima and S. gigantea have complex secondary chemistry, and variation in leaf chemistry is known to influence herbivore attack $[66,67]$. Unmeasured morphological traits may also be relevant to insect attack; for instance, Philaenus prefers plant species and individuals with wider leaf axils [94], and this trait varies among S. altissima genotypes (Maddox unpubl. in [77]). Expanding the list of measured traits, and especially incorporating leaf chemistry, is a high priority for future work.

Despite the small numbers of attacked ramets and measured traits that earn the "illustrative" dataset its descriptor, my analysis of trait-space use for four herbivores establishes that the field and analytical approach outlined here is feasible and can detect nonrandom trait-space use. Because the goldenrod system includes such a diverse herbivore community attacking syntopic ramets of the alternative hosts, it offers the potential for great progress in testing hypotheses about host trait-space use during hostshifts and HAD.

\section{General Discussion}

The literature on how insect preference and performance vary with intraspecific variation in host-plant genotype, morphology, chemistry, and phenology is immense $[95,96]$.
Similarly, interspecific variation in the same kinds of traits has been widely held up as the key to the macroevolutionary fate of herbivore lineages (host shifting, diversification, specialization, and so forth $[38,63,64,97])$. What is surprising is that the intersection of these perspectives is so little developed: we know almost nothing about trait-space use in systems where host shifting and HAD are suspected. This gap is clearly illustrated by the two best-studied cases of HAD in phytophagous insects: Eurosta solidaginis on Solidago altissima and S. gigantea and Rhagoletis pomonella on apple and hawthorn. For Eurosta, despite a wealth of information about how preference and performance relate to genetic and trait variation within S. altissima [27], few comparable data are available for flies attacking $S$. gigantea (except see [40]). For Rhagoletis, much has been written about the importance for HAD of apple-hawthorn differences in ripening phenology $[26,98,99]$ and fruit size [100]. However, data on local intraspecific variation in phenology appear to be unavailable (although latitudinal clines have been documented [26]), and data on intraspecific fruit size variation appear limited to confirming significance of interspecific differences in average fruit size [100]. This is not to criticize work on these two model systems, which has pioneered the study of HAD, but rather to draw attention to a significant opportunity for progress.

Of course, the GAP model likely falls short of recognizing the full complexity of trait-space use in nature. While I have focused on snapshots of trait variation and insect use of trait space at a single site and in a single year, both available trait space and its use are likely to vary in space and time. This variation could have interesting and important consequences for HAD. For example, intraspecific variation in Solidago phenology and the difference in average phenology between S. altissima and S. gigantea change in space and time, and phenological differences are involved in host choice for at least two Solidago herbivores undergoing HAD (Eurosta [40]; Gnorimoschema gallaesolidaginis, S. B. Heard, unpubl. data). Hawthorn phenologies show latitudinal gradients across space favouring local adaptation rather like that required during Rhagoletis' host shift to apple [26]. There are thus likely to be places or times that are more conducive to host shifts and HAD than others $[40,52,53]$. Superimposed over this variation in available trait space can be strong geographic variation in insect preference (e.g., $[82,101])$ and thus traitspace use. As a consequence, the places or times conducive to host shifting for one insect herbivore might not be so conducive for shifts by another. This is consistent with the evolutionary pattern seen in the Solidago system, in which three gallmakers have made host shifts from S. altissima to $S$. gigantea but have done so at different times [13].

Thinking about intraspecific variation in plant traits, and patterns of insect attack with respect to that variation, can expand and enhance our view of ecological speciation by phytophagous insects. Testing the hypotheses I frame about trait-space use for herbivores differing in diet breadth and in progress along the evolutionary sequence of HAD (Table 1) could take us a long way towards a predictive understanding of diet evolution and specialization in phytophagous insects. Ultimately, we would like to know for which taxa 
host-shifting and HAD are likely, and for which taxa they are not-and why $[13,38,64,102]$. While much data collection and analysis lies ahead, the trait-space perspective promises a new and powerful window on the fascinating complexity of insect-plant interactions and herbivore diversification.

\section{Acknowledgments}

The author thanks the City of Fredericton for permission to conduct field work; William Godsoe and Susan Timmons collected the field data, and William Godsoe conducted preliminary statistical analysis. He thanks Andrew Hendry and two anonymous reviewers for comments on the manuscript. John Nason and John Stireman helped shape his view of the Solidago system through collaborations, and Warren Abrahamson and John Semple have provided advice and encouragement over the years. This work was supported by Discovery Grants from the Natural Sciences and Engineering Research Council (Canada).

\section{References}

[1] D. Sharp, "Insects, part I," in The Cambridge Natural History, S. F. Harmer and A. E. Shipley, Eds., pp. 83-565, MacMillan and Co., London, UK, 1895.

[2] E. O. Wilson, The Diversity of Life, W.W. Norton, New York, NY, USA, 1992.

[3] P. J. Mayhew, "Why are there so many insect species? Perspectives from fossils and phylogenies," Biological Reviews, vol. 82, no. 3, pp. 425-454, 2007.

[4] D. R. Strong Jr., J. H. Lawton, and R. Southwood, Insects on Plants: Community Patterns and Mechanisms, Blackwell Scientific, Oxford, UK, 1984.

[5] C. Mitter, B. Farrell, and B. Wiegmann, "The phylogenetic study of adaptive zones: has phytophagy promoted insect diversification?" American Naturalist, vol. 132, no. 1, pp. 107$128,1988$.

[6] B. D. Farrell, “'Inordinate fondness' explained: Why are there so many beetles?" Science, vol. 281, no. 5376, pp. 555-559, 1998.

[7] E. A. Bernays and R. F. Chapman, Host-Plant Selection by Phytophagous Insects, Chapman and Hall, New York, NY, USA, 1994.

[8] P. D. N. Hebert, E. H. Penton, J. M. Burns, D. H. Janzen, and W. Hallwachs, "Ten species in one: DNA barcoding reveals cryptic species in the neotropical skipper butterfly Astraptes fulgerator," Proceedings of the National Academy of Sciences of the United States of America, vol. 101, no. 41, pp. 1481214817, 2004.

[9] J. B. Joy and B. J. Crespi, "Adaptive radiation of gall-inducing insects within a single host-plant species," Evolution, vol. 61, no. 4, pp. 784-795, 2007.

[10] M. A. Condon, S. J. Scheffer, M. L. Lewis, and S. M. Swensen, "Hidden neotropical diversity: Greater than the sum of its parts," Science, vol. 320, no. 5878, pp. 928-931, 2008.

[11] C. Darwin, The Origin of Species, 1968 reprint, Penguin Books, London, UK, 1859.

[12] B. D. Walsh, "The apple-worm and the apple-maggot," Tilton's Journal of Horticulture and Florist's Companion, vol. 2, pp. 338-343, 1867.

[13] J. O. Stireman, J. D. Nason, and S. B. Heard, "Host-associated genetic differentiation in phytophagous insects: General phenomenon or isolated exceptions? Evidence from a goldenrod-insect community," Evolution, vol. 59, no. 12, pp. 2573-2587, 2005.

[14] K. W. Matsubayashi, I. Ohshima, and P. Nosil, "Ecological speciation in phytophagous insects," Entomologia Experimentalis et Applicata, vol. 134, no. 1, pp. 1-27, 2010.

[15] S. H. Berlocher and J. L. Feder, "Sympatric speciation in phytophagous insects: Moving beyond controversy?” Annual Review of Entomology, vol. 47, pp. 773-815, 2002.

[16] M. Drès and J. Mallet, "Host races in plant-feeding insects and their importance in sympatric speciation," Philosophical Transactions of the Royal Society B, vol. 357, no. 1420, pp. 471-492, 2002.

[17] J. O. Stireman III, J. D. Nason, S. B. Heard, and J. M. Seehawer, "Cascading host-associated genetic differentiation in parasitoids of phytophagous insects," Proceedings of the Royal Society B, vol. 273, no. 1586, pp. 523-530, 2006.

[18] S. Skúlason, S. S. Snorrason, and B. Jónsson, "Sympatric morphs, populations and speciation in freshwater fish with emphasis on arctic charr," in Evolution of Biological Diversity, A. E. Magurran and R. M. May, Eds., Oxford University Press, Oxford, UK, 1999.

[19] A. P. Hendry, S. K. Huber, L. F. De León, A. Herrel, and J. Podos, "Disruptive selection in a bimodal population of Darwin's finches," Proceedings of the Royal Society B: Biological Sciences, vol. 276, no. 1657, pp. 753-759, 2009.

[20] J. Antonovics and A. D. Bradshaw, "Evolution in closely adjacent plant populations. 8. Clinal patterns at a mine boundary," Heredity, vol. 25, pp. 349-362, 1970.

[21] E. B. Rosenblum and L. J. Harmon, "same same but different': replicated ecological speciation at white sands," Evolution, vol. 65, no. 4, pp. 946-960, 2011.

[22] H. D. Rundle and P. Nosil, "Ecological speciation," Ecology Letters, vol. 8, no. 3, pp. 336-352, 2005.

[23] J. Peccoud and J. C. Simon, "The pea aphid complex as a model of ecological speciation," Ecological Entomology, vol. 35, no. 1, pp. 119-130, 2010.

[24] A. P. Hendry, D. I. Bolnick, D. Berner, and C. L. Peichel, "Along the speciation continuum in sticklebacks," Journal of Fish Biology, vol. 75, no. 8, pp. 2000-2036, 2009.

[25] J. L. Feder, S. H. Berlocher, and S. B. Opp, "Sympatric host-race formation and speciation in Rhagoletis (Diptera: Tephritidae): a tale of two species for Charles D," in Genetic Structure and Local Adaptation in Natural Insect Populations, S. Mopper, Ed., pp. 408-441, Chapman and Hall, New York, NY, USA, 1998.

[26] J. L. Feder, T. H. Powell, K. Filchak, and B. Leung, "The diapause response of Rhagoletis pomonella to varying environmental conditions and its significance for geographic and host plant-related adaptation," Entomologia Experimentalis et Applicata, vol. 136, no. 1, pp. 31-44, 2010.

[27] W. G. Abrahamson and A. E. Weis, Evolutionary Ecology Across Three Trophic Levels: Goldenrods, Gallmakers, and Natural Enemies, Princeton University Press, Princeton, NJ, USA, 1997.

[28] T. P. Craig and J. K. Itami, "Divergence of Eurosta solidaginis in response to host plant variation and natural enemies," Evolution, vol. 65, no. 3, pp. 802-817, 2011.

[29] S. H. Berlocher, "Radiation and divergence in the Rhagoletis pomonella species group: inferences from allozymes," Evolution, vol. 54, no. 2, pp. 543-557, 2000.

[30] J. D. Nason, S. B. Heard, and F. R. Williams, "Host-associated genetic differentiation in the goldenrod elliptical-gall moth, 
Gnorimoschema gallaesolidaginis (Lepidoptera: Gelechiidae)," Evolution, vol. 56, no. 7, pp. 1475-1488, 2002.

[31] A. M. Dickey and R. F. Medina, "Testing host-associated differentiation in a quasi-endophage and a parthenogen on native trees," Journal of Evolutionary Biology, vol. 23, no. 5, pp. 945-956, 2010.

[32] S. P. Carroll and C. Boyd, "Host race radiation in the soapberry bug: natural history with the history," Evolution, vol. 46, no. 4, pp. 1052-1069, 1992.

[33] D. J. Funk, "Isolating a role for natural selection in speciation: host adaptation and sexual isolation in Neochlamisus bebbianae leaf beetles," Evolution, vol. 52, no. 6, pp. 17441759, 1998.

[34] S. Via, A. C. Bouck, and S. Skillman, "Reproductive isolation between divergent races of pea aphids on two hosts. II. Selection against migrants and hybrids in the parental environments," Evolution, vol. 54, no. 5, pp. 1626-1637, 2000.

[35] I. Emelianov, F. Simpson, P. Narang, and J. Mallet, "Host choice promotes reproductive isolation between host races of the larch budmoth Zeiraphera diniana," Journal of Evolutionary Biology, vol. 16, no. 2, pp. 208-218, 2003.

[36] I. Ohshima, "Host-associated pre-mating reproductive isolation between host races of Acrocercops transecta: mating site preferences and effect of host presence on mating," Ecological Entomology, vol. 35, no. 2, pp. 253-257, 2010.

[37] I. Ohshima, "Host race formation in the leaf-mining moth Acrocercops transecta (Lepidoptera: Gracillariidae)," Biological Journal of the Linnean Society, vol. 93, no. 1, pp. 135-145, 2008.

[38] T. Nyman, "To speciate, or not to speciate? Resource heterogeneity, the subjectivity of similarity, and the macroevolutionary consequences of niche-width shifts in plant-feeding insects," Biological Reviews, vol. 85, no. 2, pp. 393-411, 2010.

[39] R. Walton, A. E. Weis, and J. P. Lichter, "Oviposition behavior and response to plant height by Eurosta solidaginis Fitch (Diptera: Tephritidae)," Annals of the Entomological Society of America, vol. 83, pp. 509-514, 1990.

[40] S. T. How, W. G. Abrahamson, and T. P. Craig, "Role of host plant phenology in host use by Eurosta solidaginis (Diptera: Tephritidae) on Solidago (Compositae)," Environmental Entomology, vol. 22, no. 2, pp. 388-396, 1993.

[41] T. P. Craig, J. K. Itami, W. G. Abrahamson, and J. D. Horner, "Behavioral evidence for host-race formation in Eurosta solidaginis," Evolution, vol. 47, no. 6, pp. 1696-1710, 1993.

[42] B. Schmid and C. Dolt, "Effects of maternal and paternal environment and genotype on offspring phenotype in Solidago altissima L," Evolution, vol. 48, no. 5, pp. 1525-1549, 1994.

[43] J. N. Maloof, "QTL for plant growth and morphology," Current Opinion in Plant Biology, vol. 6, no. 1, pp. 85-90, 2003.

[44] M. T. J. Johnson and A. A. Agrawal, "Plant genotype and environment interact to shape a diverse arthropod community on evening primrose (Oenothera biennis)," Ecology, vol. 86, no. 4, pp. 874-885, 2005.

[45] R. A. Rapp and J. F. Wendel, "Epigenetics and plant evolution," New Phytologist, vol. 168, no. 1, pp. 81-91, 2005.

[46] A. A. Winn, "Adaptation to fine-grained environmental variation: an analysis of within-individual leaf variation in an annual plant," Evolution, vol. 50, no. 3, pp. 1111-1118, 1996.

[47] M. C. Singer, D. Ng, D. Vasco, and C. D. Thomas, "Rapidly evolving associations among oviposition preferences fail to constrain evolution of insect diet," American Naturalist, vol. 139, no. 1, pp. 9-20, 1992.
[48] N. Janz and S. Nylin, "The role of female search behaviour in determining host plant range in plant feeding insects: a test of the information processing hypothesis," Proceedings of the Royal Society B, vol. 264, no. 1382, pp. 701-707, 1997.

[49] D. I. Bolnick, R. Svanbäck, M. S. Araújo, and L. Persson, "Comparative support for the niche variation hypothesis that more generalized populations also are more heterogeneous," Proceedings of the National Academy of Sciences of the United States of America, vol. 104, no. 24, pp. 10075-10079, 2007.

[50] D. I. Bolnick, R. Svanbäck, J. A. Fordyce et al., "The ecology of individuals: incidence and implications of individual specialization," American Naturalist, vol. 161, no. 1, pp. 1-28, 2003.

[51] L. M. Evans, G. J. Allan, S. M. Shuster, S. A. Woolbright, and T. G. Whitham, "Tree hybridization and genotypic variation drive cryptic speciation of a specialist mite herbivore," Evolution, vol. 62, no. 12, pp. 3027-3040, 2008.

[52] T. P. Craig, J. K. Itami, T. Ohgushi, Y. Ando, and S. Utsumi, "Bridges and barriers to host shifts resulting from host plant genotypic variation," Journal of Plant Interactions, vol. 6, no. 2-3, pp. 141-145, 2011.

[53] D. I. Bolnick, "Sympatric speciation in threespine stickleback: why not?" International Journal of Ecology, vol. 2011, Article ID 942847, 15 pages, 2011.

[54] M. R. Servedio and M. A. F. Noor, "The role of reinforcement in speciation: theory and data," Annual Review of Ecology, Evolution, and Systematics, vol. 34, pp. 339-364, 2003.

[55] P. Nosil, D. J. Funk, and D. Ortiz-Barrientos, "Divergent selection and heterogeneous genomic divergence," Molecular Ecology, vol. 18, no. 3, pp. 375-402, 2009.

[56] P. Nosil, S. P. Egan, and D. J. Funk, "Heterogeneous genomic differentiation between walking-stick ecotypes: "isolation by adaptation" and multiple roles for divergent selection," Evolution, vol. 62, no. 2, pp. 316-336, 2008.

[57] X. Thibert-Plante and A. P. Hendry, "When can ecological speciation be detected with neutral loci?" Molecular Ecology, vol. 19, no. 11, pp. 2301-2314, 2010.

[58] B. J. Crespi, "Vicious circles: positive feedback in major evolutionary and ecological transitions," Trends in Ecology and Evolution, vol. 19, no. 12, pp. 627-633, 2004.

[59] A. P. Hendry, "Selection against migrants contributes to the rapid evolution of ecologically dependent reproductive isolation," Evolutionary Ecology Research, vol. 6, no. 8, pp. 1219-1236, 2004.

[60] K. Räsänen and A. P. Hendry, "Disentangling interactions between adaptive divergence and gene flow when ecology drives diversification," Ecology Letters, vol. 11, no. 6, pp. 624636, 2008.

[61] A. F. Agrawal, J. L. Feder, and P. Nosil, "Ecological divergence and the origins of intrinsic postmating isolation with gene flow," International Journal of Ecology, vol. 2011, Article ID 435357, 15 pages, 2011.

[62] J. A. Coyne and H. A. Orr, Speciation, Sinauer Associates, Sunderland, Mass, USA, 2004.

[63] M. S. Singer, "Evolutionary ecology of polyphagy," in Specialization, Speciation, and Radiation: The Evolutionary Biology of Herbivorous Insects, K. J. Tilmon, Ed., pp. 29-42, University of California Press, Berkeley, Calif, USA, 2008.

[64] D. J. Funk and P. Nosil, "Comparative analyses of ecological speciation," in Specialization, Speciation, and Radiation: The Evolutionary Biology of Herbivorous Insects, K. J. Tilmon, Ed., pp. 117-135, University of California Press, Berkeley, Calif, USA, 2008. 
[65] J. C. Semple and R. E. Cook, "Solidago," in Flora of North America, Flora North America Editorial Committee, Ed., pp. 107-166, Oxford University Press, Oxford, UK, 2006.

[66] H. M. Hull-Sanders, R. Clare, R. H. Johnson, and G. A. Meyer, "Evaluation of the evolution of increased competitive ability (EICA) hypothesis: loss of defense against generalist but not specialist herbivores," Journal of Chemical Ecology, vol. 33, no. 4, pp. 781-799, 2007.

[67] R. H. Johnson, R. Halitschke, and A. Kessler, "Simultaneous analysis of tissue- and genotype-specific variation in Solidago altissima (Asteraceae) rhizome terpenoids, and the polyacetylene dehydromatricaria ester," Chemoecology, vol. 20, no. 4, pp. 255-264, 2010.

[68] G. D. Maddox and R. B. Root, "Structure of the encounter between goldenrod (Solidago altissima) and its diverse insect fauna," Ecology, vol. 71, no. 6, pp. 2115-2124, 1990.

[69] R. B. Root and N. Cappuccino, "Patterns in population change and the organization of the insect community associated with goldenrod," Ecological Monographs, vol. 62, no. 3, pp. 393-420, 1992.

[70] E. M. G. Fontes, D. H. Habeck, and F. Slansky Jr., "Phytophagous insects associated with goldenrods (Solidago spp.) in Gainesville, Florida," Florida Entomologist, vol. 77, no. 2, pp. 209-221, 1994.

[71] C. R. Weaver and D. R. King, "Meadow spittlebug," Ohio Agricultural Experiment Station Research Bulletin, vol. 741, pp. 1-99, 1954.

[72] R. B. Root and F. J. Messina, "Defensive adaptations and natural enemies of a case-bearing beetle, Exema canadensis (Coleoptera: Chrysomelidae)," Psyche, vol. 90, pp. 67-80, 1983.

[73] W. E. Miller, "Biology and taxonomy of three gall-forming species of Epiblema (Olethreutidae)," Journal of the Lepidopterists' Society, vol. 30, pp. 50-58, 1976.

[74] G. L. Waring, W. G. Abrahamson, and D. J. Howard, "Genetic differentiation among host-associated populations of the gallmaker Eurosta solidaginis (Diptera: Tephritidae)," Evolution, vol. 44, pp. 1648-1655, 1990.

[75] C. P. Blair, W. G. Abrahamson, J. A. Jackman, and L. Tyrrell, "Cryptic speciation and host-race formation in a purportedly generalist tumbling flower beetle," Evolution, vol. 59, no. 2, pp. 304-316, 2005.

[76] K. D. McCrea and W. G. Abrahamson, "Variation in herbivore infestation: historical vs. genetic factors," Ecology, vol. 68, no. 4, pp. 822-827, 1987.

[77] G. D. Maddox and R. B. Root, "Resistance to 16 diverse species of herbivorous insects within a population of goldenrod, Solidago altissima: genetic variation and heritability," Oecologia, vol. 72, no. 1, pp. 8-14, 1987.

[78] S. B. Heard and G. H. Cox, "Plant module size and attack by the goldenrod spindle-gall moth," Canadian Entomologist, vol. 141, no. 4, pp. 406-414, 2009.

[79] T. P. Craig, J. K. Itami, C. Shantz, W. G. Abrahamson, J. D. Horner, and J. V. Craig, "The influence of host plant variation and intraspecific competition on oviposition preference and offspring performance in the host races of Eurosta solidaginis," Ecological Entomology, vol. 25, no. 1, pp. 7-18, 2000.

[80] J. D. Horner and W. G. Abrahamson, "Influence of plant genotype and environment on oviposition preference and offspring survival in a gallmaking herbivore," Oecologia, vol. 90, no. 3, pp. 323-332, 1992.

[81] G. D. Maddox and N. Cappuccino, "Genetic determination of plant susceptibility to an herbivorous insect depends on environmental context," Evolution, vol. 40, pp. 863-866, 1986.

[82] K. Halverson, S. B. Heard, J. D. Nason, and J. O. Stireman, "Differential attack on diploid, tetraploid, and hexaploid Solidago altissima L. by five insect gallmakers," Oecologia, vol. 154, no. 4, pp. 755-761, 2008.

[83] K. Halverson, S. B. Heard, J. D. Nason, and J. O. Stireman, "Origins, distribution, and local co-occurrence of polyploid cytotypes in Solidago altissima (Asteraceae)," American Journal of Botany, vol. 95, no. 1, pp. 50-58, 2008.

[84] N. Moran, "The genus Uroleucon (Homoptera, Aphididae) in Michigan-key, host records, biological notes, and descriptions of 3 new species," Journal of the Kansas Entomological Society, vol. 57, pp. 596-616, 1984.

[85] S. S. Anderson, K. D. McCrea, W. G. Abrahamson, and L. M. Hartzel, "Host genotype choice by the ball gallmaker Eurosta solidaginis (Diptera: Tephritidae)," Ecology, vol. 70, no. 4, pp. 1048-1054, 1989.

[86] P. W. Price, Macroevolutionary Theory on Macroecological Patterns, Cambridge University Press, Cambridge, UK, 2003.

[87] D. T. Quiring, L. Flaherty, R. Johns, and A. Morrison, "Variable effects of plant module size on abundance and performance of galling insects," in Galling Arthropods and Their Associates: Ecology and Evolution, K. Ozaki, J. Yukawa, T. Ohgushi, and P. W. Price, Eds., pp. 189-198, Springer, Sapporo, Japan, 2006.

[88] S. B. Heard and C. K. Buchanan, "Larval performance and association within and between two species of hackberry nipple gall insects, Pachypsylla spp. (Homoptera: Psyllidae)," American Midland Naturalist, vol. 140, no. 2, pp. 351-357, 1998.

[89] J. T. Cronin and W. G. Abrahamson, "Goldenrod stem galler preference and performance: effects of multiple herbivores and plant genotypes," Oecologia, vol. 127, no. 1, pp. 87-96, 2001.

[90] J. T. Cronin and W. G. Abrahamson, "Host-plant genotype and other herbivores influence goldenrod stem galler preference and performance," Oecologia, vol. 121, no. 3, pp. 392404, 1999.

[91] E. A. Lehnertz, Impacts of herbivory in a goldenrod/insect community: effects of early-season herbivores on host plants and a late-season herbivore, M.S. thesis, University of Iowa, Iowa, Canada, 2001.

[92] D. C. Hartnett and W. G. Abrahamson, "The effects of stem gall insects on life history patterns in Solidago canadensis," Ecology, vol. 60, pp. 910-917, 1979.

[93] S. B. Heard and E. K. Kitts, "Impact of attack by Gnorimoschema gallmakers on their ancestral and novel Solidago hosts," Evolutionary Ecology. In press.

[94] P. B. McEvoy, "Niche partitioning in spittlebugs (Homoptera: Cercopidae) sharing shelters on host plants," Ecology, vol. 67, no. 2, pp. 465-478, 1986.

[95] S. Gripenberg, P. J. Mayhew, M. Parnell, and T. Roslin, "A meta-analysis of preference-performance relationships in phytophagous insects," Ecology Letters, vol. 13, no. 3, pp. 383393, 2010.

[96] D. Carmona, M. J. Lajeunesse, and M. T. Johnson, "Plant traits that predict resistance to herbivores," Functional Ecology, vol. 25, no. 2, pp. 358-367, 2011.

[97] N. Janz and S. Nylin, "The oscillation hypothesis of hostplant range and speciation," in Specialization, Speciation, and Radiation: The Evolutionary Biology of Herbivorous Insects, K. J. Tilmon, Ed., pp. 29-42, University of California Press, Berkeley, Calif, USA, 2008. 
[98] J. L. Feder, T. A. Hunt, and L. Bush, "The effects of climate, host plant phenology and host fidelity on the genetics of apple and hawthorn infesting races of Rhagoletis pomonella," Entomologia Experimentalis et Applicata, vol. 69, no. 2, pp. 117-135, 1993.

[99] H. R. Dambroski and J. L. Feder, "Host plant and latituderelated diapause variation in Rhagoletis pomonella: a test for multifaceted life history adaptation on different stages of diapause development," Journal of Evolutionary Biology, vol. 20, no. 6, pp. 2101-2112, 2007.

[100] J. L. Feder, "The effects of parasitoids on sympatric host races of Rhagoletis pomonella (Diptera: Tephritidae)," Ecology, vol. 76, no. 3, pp. 801-813, 1995.

[101] M. S. Singer, B. Wee, S. Hawkins, and M. Butcher, "Rapid natural and anthropogenic diet evolution: three examples from checkerspot butterflies," in Specialization, Speciation, and Radiation: The Evolutionary Biology of Herbivorous Insects, K. J. Tilmon, Ed., pp. 311-324, University of California Press, Berkeley, Calif, USA, 2008.

[102] D. J. Funk, "Does strong selection promote host specialisation and ecological speciation in insect herbivores? Evidence from Neochlamisus leaf beetles," Ecological Entomology, vol. 35 , no. 1, pp. 41-53, 2010. 

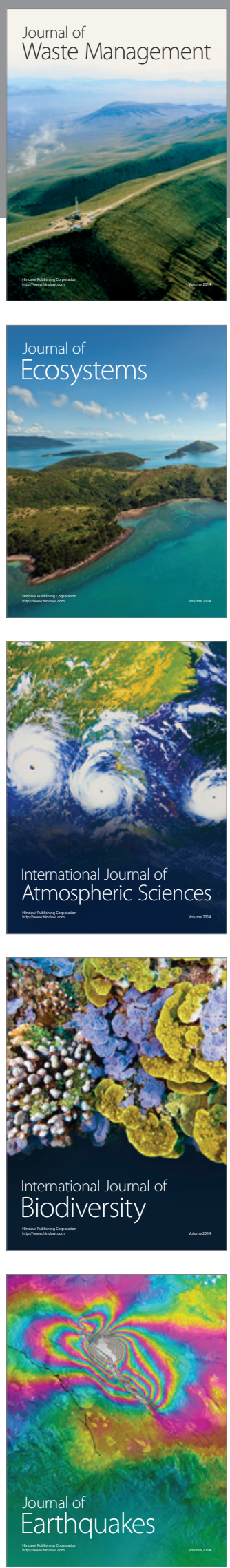
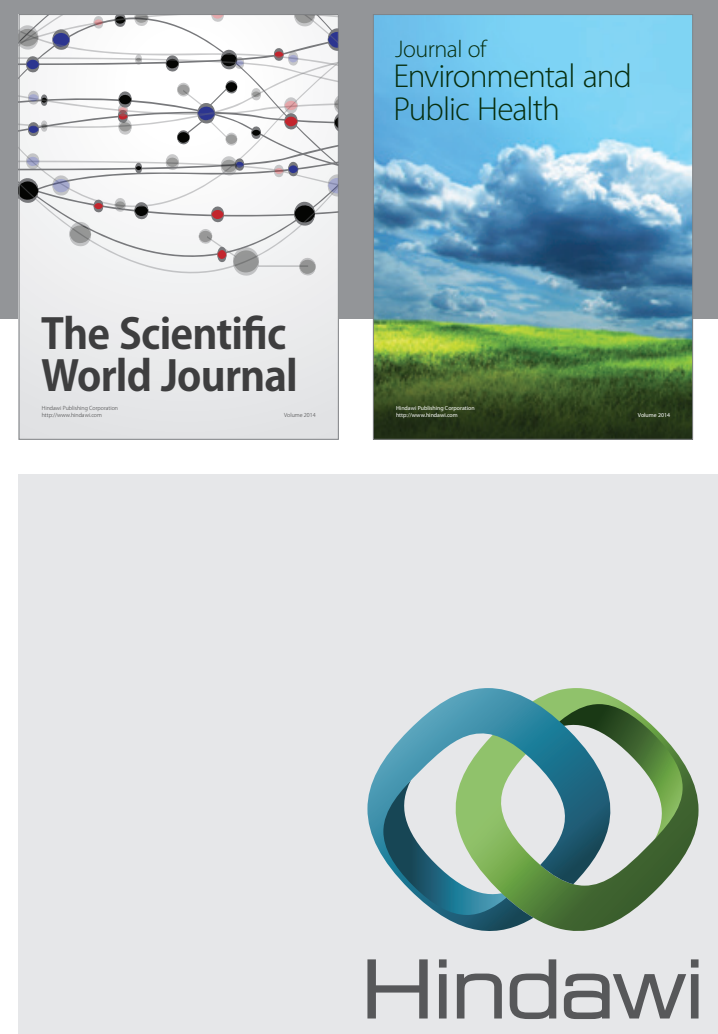

Submit your manuscripts at

http://www.hindawi.com
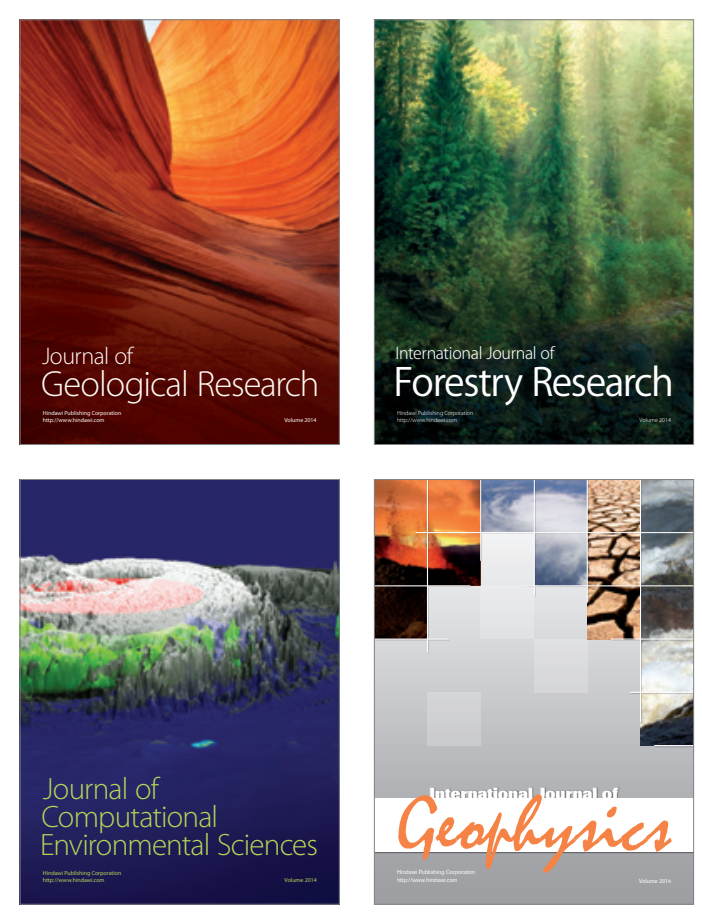
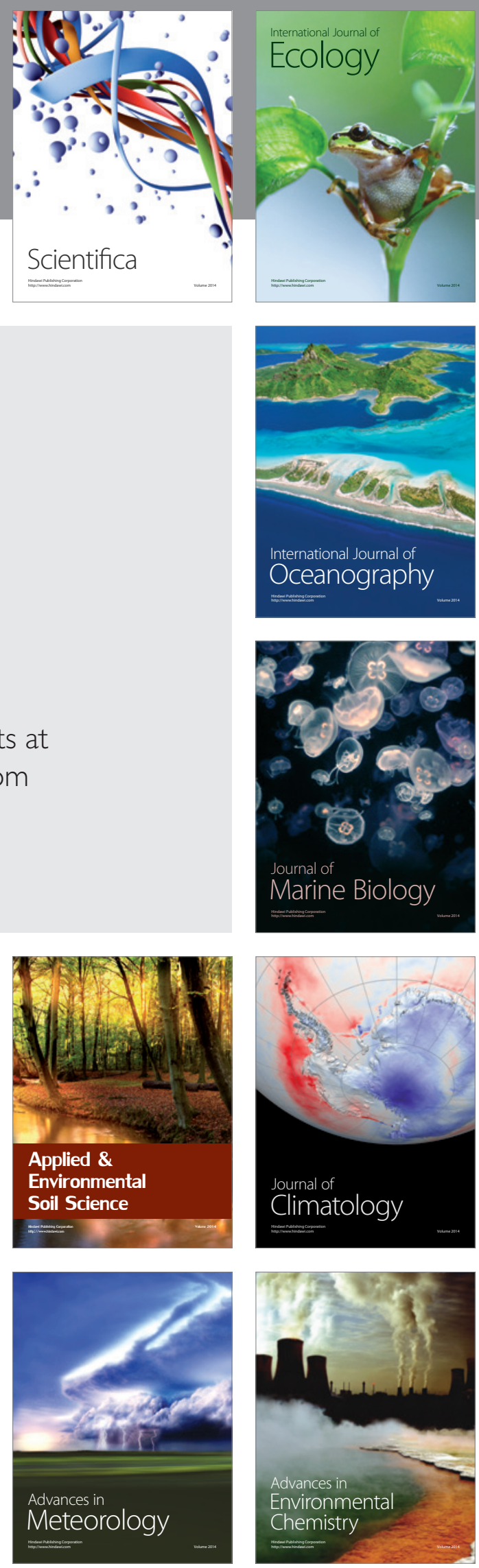